should ensure that the immunity of older children is maintained.

It is conceivable that in future those responsible for mass immunization programmes may have to combat not only indifference to vaccination but also active opposition arising from the fact that the vaccine carries a remote risk of causing paralytic poliomyelitis. The risk was found to be less than one case per million doses of vaccine used in the U.S.A. during $1961-3^{2}$ and $1964-8,{ }^{3}$ whereas in England and Wales it was one case per four million doses of vaccine used during 1962-4 and $1965-8 .^{5}$ Vaccine-associated paralytic poliomyelitis is not necessarily restricted to recipients of vaccine but may involve close contacts. ${ }^{3} 5$ Nevertheless, if the vaccination programme were to be fully carried out in this country, it is highly unlikely that there would be more than four vaccine-associated cases of paralytic poliomyelitis per year. Since completion of a mass vaccination programme almost completely suppresses paralytic poliomyelitis due to wild virus but at the same time may cause paralytic poliomyelitis on rare occasions, there could in future be more new paralytic cases attributable to the vaccine virus than to wild virus. If vaccination were neglected, however, outbreaks of poliomyelitis, such as that in Blackburn during $1965,{ }^{6}$ are likely, particularly since there is a constant and substantial risk of the virus being imported. There were 707 new cases of paralytic poliomyelitis and 59 deaths in England and Wales in 1961, the last year before live vaccine was used here on a large scale. All were due to wild virus. In 1969 there were only 9 cases, and there have been no deaths since $1966 .^{7}$ The choice is clear: a fully carried out vaccination programme, which carries a remote risk of paralytic poliomyelitis, or a neglected programme, which could allow the wild virus to cause new outbreaks. The biggest problem confronting us to-day is one of public apathy. It erodes vaccination programmes.

1 World Health Statistics Report, 1970, 23, No. 8.

2 Henderson, D. A., Witte, J. J., Morris, L., and Langmuir, A. D., Fournal of the American Medical Association, 1964, 190, 41.

Hopkins, C. C., Dismukes, W. E., Glick, T. H., and Warren, R. J., Fournal of the American Medical Association, 1969, 210, 694.

4 Miller, D. L., and Galbraith, N. S., British Medical fournal, 1965, 2, 504 Miller, D. L., Reid, D., and Diamond, J. R., Public Health (London), $1970,84,265$.

Moss, P. D., Durge, N. D., Robertson, L., and Cowburn, G. R., Lancet, $1968,2,555$.

Annual Report of the Chief Medical Officer of the Department of Health and Social Security for the Year 1969. London, H.M.S.O., 1970.

\section{Cytomegalovirus Infection}

Infection is not the same thing as disease. If an organism invades the body and multiplies in it, that is infection, but it may be silent and cause no reaction in the body other than a rise in antibody. In disease, on the other hand, the invading organism causes damage to tissues. This may be so slight that the patient has no symptoms and the damage can be detected only by laboratory tests. Many organisms can affect the human body in this way-in inapparent rubella, for example, subclinical poliomyelitis, or toxoplasmosis. Cytomegalovirus is another organism whose passage through the body is most often silent, though it can produce manifest disease.

In Sweden it has been estimated that over $90 \%$ of people aged 65 have been infected with cytomegalovirus, ${ }^{1}$ yet illness due to cytomegalovirus infection has rarely been diagnosed in that country. ${ }^{2}$ Part of the failure to detect cytomegalovirus disease is due to failure to look for it, but even when it is carefully sought few cases of symptomatic infection are found.
G. Sterner and his colleagues ${ }^{3}$ found only 17 cases in three years in Stockholm, though in one of the years 300 patients were studied with cytomegalovirus infection in mind. In their search they concentrated on patients with fever and atypical lymphocytes, patients thought to have septicaemia, and patients transferred from surgical wards because of unexplained fever. Paired sera were examined for complementfixing antibodies, and urine for the presence of cytomegalovirus. The commonest symptom in the 17 patients was continued fever; the commonest findings were abnormal liver-function tests in all and atypical lymphocytes in the blood films of more than half. Sixteen of the 17 patients appeared well in spite of their fever.

Cytomegalovirus is like rubella virus in that, while it causes little damage to mature host cells, it destroys or severely damages fetal cells. Intrauterine cytomegalovirus infection tends, therefore, to cause severe congenital disease. The baby is born prematurely and obviously diseased. He is jaundiced and lethargic and his breathing is distressed. Often he has a purpuric rash, his liver and spleen are enlarged, he is anaemic and may have convulsions. Most of these infants die within a few days of birth, but a few recover, probably those few in whom the lungs and the brain have not been affected. ${ }^{4}$ Some infected babies are born apparently normal but later show signs of severe brain damage, such as microcephaly, spastic diplegia, epilepsy, or blindness. These are all effects of the wide dissemination of the virus in developing fetal tissue. When an infant is infected after birth, the infection, by contrast, is usually silent. In necropsies of infants dying from other causes cytomegalovirus may be isolated from the salivary glands and the urine in as many as $10 \%$ with no evidence at all of any pathological changes due to the virus. In older children infection is common, especially in institutions, where in some instances half the children may be infected, excreting the virus in their urine or saliva for months or years, ${ }^{5}$ yet showing no evidence of disease except, in a few, some enlargement of the liver. Very seldom does the infection break through to the clinical level as a rare cause of jaundice or of a prolonged fever in a child.

Symptomatic infections are seen more often in adults, and fever is the commonest symptom. The temperature is high and spiky and may continue for several weeks, yet the patient complains of little discomfort other than passing aches and pains. Serum bilirubin is normal, or only slightly raised, but there is usually a slight rise in some of the other tests of liver function, especially in transaminase levels. The white cell count may vary from 2,000 to over $20,000 / \mathrm{mm}^{3}$, and atypical lymphocytes are often present. The blood picture and the liver-function tests may suggest infectious mononucleosis, and sometimes patients with cytomegalovirus disease have transient enlargement of lymph nodes, but in them the Paul-Bunnell test is always negative, as are immunofluorescent and complement-fixation tests for rising antibody titres against Epstein-Barr (EB) virus. Toxoplasmosis is another disease which presents with continued fever, lymphadenopathy, atypical lymphocytes, and negative Paul-Bunnell test, but the dye test and complement-fixation tests are strongly positive. If cytomegalovirus infection is suspected the urine should be examined for giant cells and cultured in human diploid cells for virus. Blood and other body fluid or tissue may also be cultured, and paired sera examined for rising antibody titre. If virus is isolated, and there is a rising serum antibody titre; this suggests that cytomegalovirus is the cause of the illness. If giant cells are also detected, this is further evidence of active cytomegalovirus disease. 
Very occasionally patients with cytomegalovirus disease have more marked symptoms. Jaundice, ${ }^{6}$ pneumonia, encephalitis, and exudative tonsillitis have been described. ${ }^{3}$ But a Paul-Bunnell-negative syndrome like infectious mononucleosis with fever is much the commonest picture. It is scarcely possible to trace the source of infection. Contact with another febrile patient in the family, or with newborn babies is sometimes reported, ${ }^{3}$ and the disease should certainly be suspected when patients have an unexplained febrile illness after blood transfusion ${ }^{78}$ or open-heart ${ }^{9}$ or transplant surgery. ${ }^{10}$ Such patients are usually debilitated and some are being treated with immunosuppressive drugs. A latent cytomegalovirus infection might flare up under those conditions. The alternative, that the virus is conveyed in the blood or the transplant from the donor to the recipient, must be regarded as a possible hazard of these operations. Cytomegalovirus infection is usually silent, but in severe disease of the newborn or unexplained pyrexia in adults it should be considered in the differential diagnosis.

Wahren, B., Espmark, $\AA$., and Walldén, G., Scandinavian fournal of Infectious Diseases, 1969, 1, 145.

2 Carlsträm, G., et al., British Medical fournal, 1968, 2, 521.

Sterner, G., Agell, B.-O., Wahren, B., and Espmark, Å., Scandinavian fournal of Infectious Diseases, 1970, 2, 95.

4 Christie, A. B., Infectious Diseases: Epidemiology and Clinical Practice, p. 950 . Edinburgh, Livingstone, 1969.

Diosi, P., Babusceac, L., Nevinglovsch, O., and Stoicanescu, A., Pathologia Microbiologica, 1966, 29, 513.

Lamb, S. G., and Stern, H., Lancet, 1966, 2, 1003.

Kääriäinen, L., Klemola, E., and Paloheimo, J., British Medical fournal, 1966, 1, 1270.

' Foster, K. M., and Jack, I., New England fournal of Medicine, 1969, 280, 1311 .

Paloheimo, J. A., Von Essen, R. Klemola, E., Kääriäinen, L., and Siltanen, P., American fournal of Cardiology, 1968, 22, 624.

10 Rifkind, D., Archives of Internal Medicine, 1965, 116, 554.

\section{Selection in Maintenance Haemodialysis}

Though it is 11 years since B. H. Scribner's original patient with terminal renal failure started his long-term dialysis odyssey, ${ }^{1}$ the dilemma of who shall live and who shall die is as poignant as ever. The need to choose which patients are to die from terminal renal failure is because treatment facilities are insufficient owing to shortages of staff and money. ${ }^{2}$ Over six years ago home dialysis was introduced as an economic necessity in order to enable more patients to benefit from treatment. ${ }^{3}$ In spite of its remarkable success, less than $30 \%$ of the population, or 2,000 new patients each year, ${ }^{4}$ requiring treatment in the United Kingdom have a chance of receiving it. Elsewhere in the world facilities are no better and in many areas are worse. Consequently some form of patient selection is practised.

A phrase often used in selection is "medically suitable." The criteria of suitability have recently been defined by E. Reisin and co-workers ${ }^{5}$ from retrospective analysis of survival. Suitable patients were defined as below 50 years of age, suffering from terminal renal failure due to primary renal disease, free from other systemic diseases, co-operative and emotionally stable, and without long-standing hypertension, heart failure, coronary-artery, cerebrovascular, or peripheral vascular disease, or clinically evident polyneuropathy. In a series of 30 patients treated for up to four years only one out of seven unsuitable patients survived two years, whereas out of 19 suitable patients who received treatment for 15 to 20 months only two died. However, only two survived for over 26 months. The authors concluded that medical selection is necessary to obtain the greatest benefit from this scarce form of therapy.

But these conclusions would not be generally accepted in the United Kingdom and the U.S.A. For instance, outstanding results were achieved by J. F. Moorehead and colleagues, ${ }^{6}$.who reported an $86 \%$ four-year survival without any medical selection. S. L. Cohen and co-workers ${ }^{7}$ have reported no difference in survival in their patients aged over 50 compared with younger patients, and E. J. Lewis and colleagues confirmed this in a larger series. ${ }^{8} \mathrm{~J}$. S. Cameron and colleagues ${ }^{9}$ have reported that children do better on longterm dialysis than adults, and S. Shaldon and his colleagues ${ }^{10}$ have been shown that home dialysis in children produces equivalent results to those in adults. It would appear that in centres achieving the best periods of survival age is no longer a criterion for medical selection. Furthermore, the average results reported in the 1970 European dialysis and transplant survey ${ }^{11}$ show $63 \%$ surviving for three years.

The major causes of death have been sepsis associated with shunt infections, heart failure, and uncontrolled hypertension and hyperkalaemia. Shunt sepsis can now be eliminated with the use of the arteriovenous fistula, ${ }^{12}$ and the latter two causes can be controlled with more frequent dialysisnamely, three times a week instead of twice. The results obtained by Moorehead and colleagues, largely in home dialysis patients, were based on dialysis three times a week. It is usual for patients on home dialysis to have it that frequently, whereas for hospital dialysis twice-weekly treatment is commoner. Other factors favourable to home dialysis are the reduced risks of cross-infection and hepatitis.

The better survival and economic benefits indicate that most maintenance dialysis should be done in the home. Unfortunately not all patients are suitable for home dialysis, and it has been suggested that it is not ethical to select patients only on the grounds of suitability for dialysis at home. ${ }^{13}$ On economic grounds this argument cannot be sustained, for as long as selection has to be practised it may well be argued, if age and disease status are no longer criteria, that the utilization of limited facilities for the greatest cost-effectiveness is the best determinant. On these grounds permanent maintenance dialysis in a hospital centre would not win support. The alternative for patients unsuitable for home dialysis appears to be transplantation, though the survival results of cadaver transplantation are still inferior to those of maintenance haemodialysis. ${ }^{11}$ Despite the progress made in the past 10 years and the millions of pounds spent on maintenance haemodialysis, selection for this form of treatment will remain a doctor's dilemma for many years to come.

Scribner, B. H., Buri, R., Caner, J. E. Z., Hegstrom, R., and Burnell, J. M., Transactions of the American Society for Artificial Internal Organs, 1960, 6, 114

British Medical fournal, 1971, 1, 301.

Baillod, R. A., et al., Proceedings of the European Dialysis and Transplant Association, 1965, 2, 99.

Kerr, D. N. S., Proceedings of the Royal Society of Medicine, 1967, 60, 1195.

Reisin, E., Feng, P. H., Weinberg, U., Iaina, A., and Eliahou, H. E., Israel fournal of Medical Sciences, 1970, 6, 677.

6 Moorehead, J. F., et al., British Medical fournal, 1970, 4, 83.

Cohen, S. L., Comty, C. M., and Shapiro, F. L., Proceedings of the European Dialysis and Transplant Association, 1970, 7, 254.

${ }^{8}$ Lewis, E. J., Foster, D. M., de la Puente, J., and Sculock, C., Annals of Internal Medicine, 1969, 70, 311.

- Cameron, J. S., et al., Proceedings of the European Dialysis and Transplant Association, 1970, 7, 25 .

10 Shaldon, S., Shaldon, J., McInnes, S., MacDonald, H., and Oag, D., Proceedings of the European Dialysis and Transplant Association, 1969, 6, 145.

11 Gurland, H. J., Harlen, H., Henze, H., and Spoek, M. G., Proceedings of the European Dialysis and Transplant Association, 1970, 7, 20.

12 Shaldon, S., and McKay, S., British Medical fournal, 1968, 4, 671.

13 Gordon, P. M., and Cattell, W. R., Proceedings of the European Dialysis and Transplant Association, 1970, 7, 248. 